\title{
New light into the hormogastrid riddle: morphological and molecular description of Hormogaster joseantonioi sp. n. (Annelida, Clitellata, Hormogastridae)
}

\author{
Daniel Fernández Marchán ${ }^{1, \dagger}$, Rosa Fernández ${ }^{2, \ddagger}$, \\ Marta Novo ${ }^{3, \$}$, Darío J. Díaz Cosín ${ }^{1,1}$
}

I Departamento de Zoología y Antropología Física, Facultad de Biología, Universidad Complutense de Madrid, C/ José Antonio Nováis 2, 28040, Madrid, Spain 2 Museum of Comparative Zoology, Department of Organismic and Evolutionary Biology, Harvard University, 26 Oxford Street, Cambridge, MA 02138, USA 3 Cardiff School of Biosciences, Cardiff University, BIOSI 1, Museum Avenue, Cardiff CF10 3AT, UK

† http://zoobank.org/CAB83B57-ABD1-40D9-B16A-654281D71D58

† http://zoobank.org/99618966-BB50-4A01-8FA0-7B1CC31686B6

§ http://zoobank.org/79DA5419-91D5-4EAB-BC72-1E46F10C716A

| http://zoobank.org/38538B17-F127-4438-9DE2-F9D6C597D044

Corresponding author: Daniel Fernández Marchán (danifermch@gmail.com)

Academic editor: R. Blakemore | Received 7 April 2014 | Accepted 26 May 2014 | Published 5 June 2014

http://zoobank.org/8C6549A9-B40D-4447-8E37-62224B9EAA17

Citation: Marchán DF, Fernández R, Novo M, Cosín DJD (2014) New light into the hormogastrid riddle: morphological and molecular description of Hormogaster joseantonioi sp. n. (Annelida, Clitellata, Hormogastridae). ZooKeys 414: 1-17. doi: $10.3897 /$ zookeys.414.7665

\begin{abstract}
The earthworm family Hormogastridae shows a remarkable disjunction in its distribution in the Iberian Peninsula, with the Hormogaster elisae species complex isolated from the rest of the species. Hormogaster joseantonioi sp. n., a new species found in the intermediate area between the main ranges (in Teruel, Aragón), was described following the integrative approach, as it is suitable for earthworms due to their highly homoplasic morphology. The phylogenetic analysis of the molecular markers placed the new species as a sister taxon to $H$. elisae, thus showing the colonizing lineage of Central Iberian Peninsula could have originated near the $H$. joseantonioi sp. n. current range. External morphological characters revealed some degree of overlap with previously described species, but internal characters presented configurations/ states unknown from other members of the family. These traits make the new species a key piece to understand the evolution of Hormogastridae.
\end{abstract}

Copyright D.F.Marchán et al. This is an open access article distributed under the terms of the Creative Commons Attribution License (CC BY 4.0), which permits unrestricted use, distribution, and reproduction in any medium, provided the original author and source are credited. 


\section{Keywords}

Species description, earthworm, integrative taxonomy, phylogeny, disjunct distribution

\section{Introduction}

The increasing availability of molecular and ecological data has placed the integrative taxonomy (as defined by Dayrat 2005) as a viable alternative to traditional species description. Several authors advocate its use in different animal groups (Padial and De La Riba 2010; Schlick-Steiner et al. 2010; Heethoff et al. 2011; but see Yeates et al. 2011 for iterative taxonomy instead) and particularly in earthworms (Blakemore and Kupriyanova 2010; Novo et al. 2012), whose taxonomy is in need of deep revision in the light of molecular phylogeny (Jamieson et al. 2002; Pop et al. 2003, 2007; Chang et al. 2008; Briones et al. 2009; Pérez-Losada et al. 2009, 2011; Novo et al. 2011; Fernández et al. 2012).

Fernández et al. (2014) have developed a new tool based in micro-computed tomography to study specimens in a non-destructive way which could help as an additional source of information.

Taxonomic characters traditionally used for the study of earthworms are few and sometimes present high intraspecific variability (Michaelsen 1900 and Stephenson 1930 on their global fauna; Pop et al. 2003 and Briones et al. 2009 about lumbricid earthworms). Recent findings show that cryptic diversity is common in these animals (but see critique in Blakemore et al. 2010), therefore earthworm taxonomy can particularly benefit from an integrative approach.

Novo et al. (2011) presented a molecular phylogeny of Hormogastridae (Oligochaeta, Annelida), whose taxonomy has historically been built on morphological characters, which highlighted some interesting evolutionary aspects. On one hand, hormogastrid distribution across the Western Mediterranean is biogeographically consistent, reflecting the geological events that affected the region in the Tertiary (which confirms previous studies, e.g Bouché 1972, Sbordoni et al. 1992). Two species -Xana omodeoi Diaz Cosin, Briones \& Trigo, 1989 and the morphospecies Hormogaster elisae Álvarez, 1977 -, however, are found in locations far apart from the family main range in the Iberian Peninsula. While all the other Iberian species are distributed in Northeastern Spain, X. omodeoi inhabits Northwestern Spain and H. elisae is found in Central Spain (Segovia, Madrid and Guadalajara). The result is a disjunct distribution.

Novo (2010) found Hormogaster elisae complex to be monophyletic, and thus the likely result of a single colonisation event presumably from the North or the East of the Iberian Peninsula. There could be remaining populations of the migrating lineage in the geographic gap, which haven't been discovered yet.

On the other hand, it seems that most key characters used for hormogastrid traditional taxonomy and phylogeny (notably the shape, number and position of the spermathecae) are highly homoplasic, showing little or no phylogenetic signal across the family. 
Due to its relevance for this subject, the intermediate area between the main ranges of hormogastrids in Spain has been subject to recent sampling campaigns. Both Zaragoza and Teruel (Aragón, Spain) were suitable regions as they have been poorly sampled for earthworms unlike the surrounding provinces. While no success was met in Zaragoza, a population assignable to a new species of Hormogastridae was recently found in Teruel.

This paper focuses on the description of Hormogaster joseantonioi sp. $n$. from an integrative point of view, following the example of Novo et al. (2012). The new molecular and morphological data are interpreted to gain insight into the diversification and morphological radiation of the family, with some considerations about its constituent genera.

\section{Materials and methods}

\section{Earthworm specimens and sampling points}

Specimens were collected by hand and fixed in the field in ca. $96 \% \mathrm{EtOH}$, with subsequent alcohol changes. Once in the laboratory, specimens were preserved at $-20{ }^{\circ} \mathrm{C}$.

The studied material includes 10 specimens (five mature specimens, one semimature specimen with tubercula pubertatis and four immatures) collected in a cleared holm-oak wood at the foothill of Sierra de Oriche, road A-2514 between Huesa del Común and Rudilla, Teruel (Spain) $\left(41^{\circ} 0^{\prime} 55.68^{\prime \prime} \mathrm{N}, 0^{\circ} 58^{\prime} 55.98^{\prime \prime W}\right)$ (Figure 1).

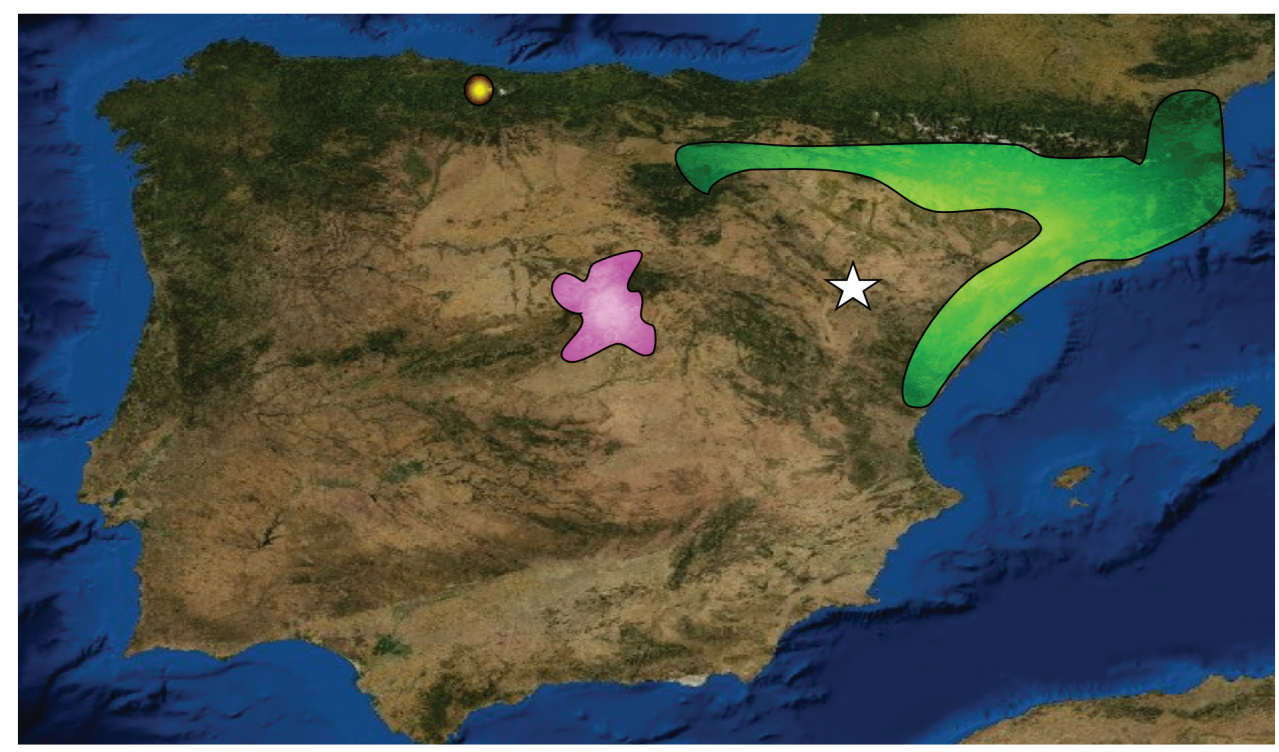

Figure I. Map of the Iberian Peninsula showing the collection site of $H$. joseantonioi sp.n. (indicated by the white star). The northeastern hormogastrid range is shown in green, H. elisae range is shown in pink and $X$. omodeo $i$ known location is indicated in yellow. 
Specimens have been deposited in the Oligochaete collection of the Departamento de Zoología y Antropología Física, Universidad Complutense de Madrid (UCMLT), Spain with vouchers UCMLT 00001-00010.

Specimens available from previous studies (Novo et al. 2010, 2011, 2012) of all known hormogastrid species were used for comparison. Morphological characters include those features traditionally used for hormogastrids and other earthworms.

\section{Molecular data generation}

Total genomic DNA was extracted from ventral integument tissue samples using the DNeasy Tissue Kit (QIAGEN) with two consecutive steps of elution (70 $\mu$ l of buffer). Seven molecular regions were amplified: mitochondrial subunit 1 of cytochrome $c$ oxidase (COI), 16S rRNA and tRNA Leu, Ala, and Ser (16S t-RNAs), one nuclear ribosomal gene (a fragment of $28 \mathrm{~S}$ rRNA) and one nuclear protein-encoding gene (histone $\mathrm{H} 3$ ). Primer sequences, polymerase chain reactions (PCR) and sequencing reactions are the same as in Novo et al. (2011). GeneBank accession numbers for the holo- and paragenetypes, following Chakrabarty (2010) for the markers analysed here are shown in Table 1.

\section{Phylogenetic analyses}

The new sequences were combined with all the hormogastrid information available from previous studies (Novo et al. 2010, 2011, 2012) in order to find their phylogenetic placement inside the family. Pontodrilus litoralis Grube, 1855, Dichogaster saliens Beddard, 1893, Amynthas robustus Perrier, 1872, Lumbricus terrestris Linnaeus, 1758 and Aporrectodea trapezoides Dugès, 1828 were used as outgroups (all the GenBank accession numbers are shown in Appendix). As hormogastrid individuals from

Table I. Holo- and paragenetypes (sensu Chakrabarty, 2010) of H. joseantonioi sp. n., and their GenBank accession numbers. The hologenetype is shown in bold.

\begin{tabular}{c|c|c|c|c|c}
\hline Specimen & Voucher & COI & 16S-tRNAs & 28S rRNA & H3 \\
\hline HRUD1 & UCMLT 00001 & KJ632674 & KJ632684 & KJ632686 & KJ632688 \\
\hline HRUD2 & UCMLT 00002 & KJ632675 & KJ632685 & KJ632687 & KJ632689 \\
\hline HRUD3 & UCMLT 00003 & KJ632676 & & & \\
\hline HRUD4 & UCMLT 00004 & KJ632677 & & & \\
\hline HRUD5 & UCMLT 00005 & KJ632678 & & & \\
\hline HRUD6 & UCMLT 00006 & KJ632679 & & & \\
\hline HRUD7 & UCMLT 00007 & KJ632680 & & & \\
\hline HRUD8 & UCMLT 00008 & KJ632681 & & & \\
\hline HRUD9 & UCMLT 00009 & KJ632682 & & & \\
\hline HRUD10 & UCMLT 00010 & KJ632683 & & & \\
\hline
\end{tabular}


the same locality usually cluster together, one individual was analysed as representative per sampling site.

Sequences of each individual gene were aligned in MAFFT (Katoh and Standley 2013 ) with default settings and concatenated, resulting in a matrix of $2532 \mathrm{bp}$. jModelTest v. 2.1.3 (Darriba et al. 2012) was used to select the best-fit evolutionary model using the Akaike information criterion (AIC; Akaike 1973), and Bayesian information criterion (BIC; Schwarz 1978) which were GTR $+\mathrm{I}+\mathrm{G}$ for COI, 16s and 28s, and $\mathrm{HKY}+\mathrm{I}+\mathrm{G}$ for $\mathrm{H} 3$.

Bayesian Inference (BI) of the phylogeny was estimated with MRBAYES v.3.1.2 (Ronquist and Huelsenbeck 2003) implemented in the CIPRES Science Gateway V. 3.3. (http://www.phylo.org/index.php/portal/). Unlinked nucleotide substitution models selected were specified for each gene fragment and the nucleotide substitution estimates were allowed to vary independently between each partition. Parameters were set to ten million generations and 10,000 trees were sampled for every 1000th generation, initiating the analysis from a random tree. After two analysis were performed $20 \%$ of the trees were discarded as burn-in, and the remaining trees were combined to find the maximum a posteriori probability estimate of phylogeny. Maximum likelihood analyses were performed with RAxML 7.2.7 (Stamatakis 2006) in the CIPRES Science Gateway with default settings, using GTR $+\mathrm{I}+\mathrm{G}$ for each data partition and estimating the support for the resulting topologies by 100 bootstrap replicates.

Uncorrected pairwise differences for the mitochondrial regions were calculated between $H$. joseantonio $i$ and the most closely related species with Arlequin 3.5 (Excoffier and Lischer 2010. To visualize the genetic distance we constructed networks with SplitsTree4 v.4.11.3 (Huson and Bryant 2006) for the more variable genes, including the former species plus Hormogaster riojana Qiu \& Bouché, 1998 and A. trapezoides as outgroups. Default settings were used.

\section{Results}

\section{Taxonomic results}

Phylum Annelida Lamarck, 1802

Subphylum Clitellata Michaelsen, 1919

Class Oligochaeta Grube, 1850

Superorder Megadrilacea Benham, 1890

Order Haplotaxida Michaelsen, 1900

Family Hormogastridae Michaelsen, 1900

Genus Hormogaster Rosa, 1887

Type-species. Hormogaster redii Rosa, 1887. 


\section{Hormogaster joseantonioi Fernández Marchán, sp. n.} http://zoobank.org/1B7B13C0-FA56-466E-9FFE-AB985EB582BA http://species-id.net/wiki/Hormogaster_joseantonioi

Material examined. Holotype. Adult (UCMLT 00003), $41^{\circ} 0^{\prime} 55.68^{\prime \prime} \mathrm{N}, 0^{\circ} 58^{\prime} 55.98^{\prime \prime W}$, from a cleared holm-oak wood on the foothill of Oriche mountains, road A-2514 between Huesa del Común and Rudilla, Teruel (Spain), collectors D. Fernández Marchán and J.A. Fernández Fernández.

Paratypes. Nine individuals (UCMLT 00001, 00002, 00004-00010), with the same collection data of the holotype.

Other material examined. 16 hormogastrid species and several subspecies belonging to the UCMLT collection.

Morphological description. External morphology (Figure 2). * Measures taken on the two only complete specimens, one being the holotype.

Length of mature specimens*: $178-180 \mathrm{~mm}$.

Maximum diameter (pre-clitellar, clitellar, post-clitellar) of mature specimens: 8-10, 9-11, 7-10 mm.

Number of segments*: 305-369.

Weight (fixed specimens)*: 7.05-11.57 g.

Colour: From light brown to dark chocolate brown varying between individuals, with orangeish-brown clitellum of a lighter shade on living specimens (Figure 2a). Beige with brown stripes or patches, mainly on the anterior end, with darker clitellum on fixed specimens (Figure $2 \mathrm{~b}$ ).

Prostomium prolobic, longitudinal striation on segments 1 and 2 .

Closely paired chaetae; interchaetal ratio at segment 40, aa: 33, ab: 1.3, $b c: 6, c d$ : $1, d d: 27$. Nephridial pores in a row between chaetae $b$ and $c$ (very close to $b$ ), visible on fixed specimens as a brownish line.

Spermathecal pores at intersegments $9 / 10$ and $10 / 11$ at the level of $c d$.

Male pores open over chaetae $a b$ at the intersegment 15/16, surrounded by heartshaped porophores which extend over most of segment 15 and at least half of 16 . Female pores in segment 14 at the same level as male pores.

Clitellum saddle-shaped extending over segments (13) 14-28. Tubercula pubertatis on $1 / \mathrm{n} 22-27(1 / \mathrm{n} 28)$ as a continuous line. Papillae of chaetae ab in variable positions, usually between segments 12 and 28: papillae on 12 always showing an unusual degree of development in mature individuals, being very conspicuous both in live and fixed specimens (Figure 2a).

Internal anatomy. Funnel shaped, strongly thickened septa in $6 / 7,7 / 8$ and $8 / 9$, septum 9/10 slightly thickened. The latter's attachment to the dorsal body wall is displaced two segments backwards, creating a mismatch between inner and outer segmentation with an internally very wide segment 9 .

Last pair of hearts in segment 11 . Three shiny, strongly muscular gizzards in 6,7 and 8. Not apparent Morren's glands, even though small wrinkles exist in the oesophageal wall between segments 10 and 16 . 


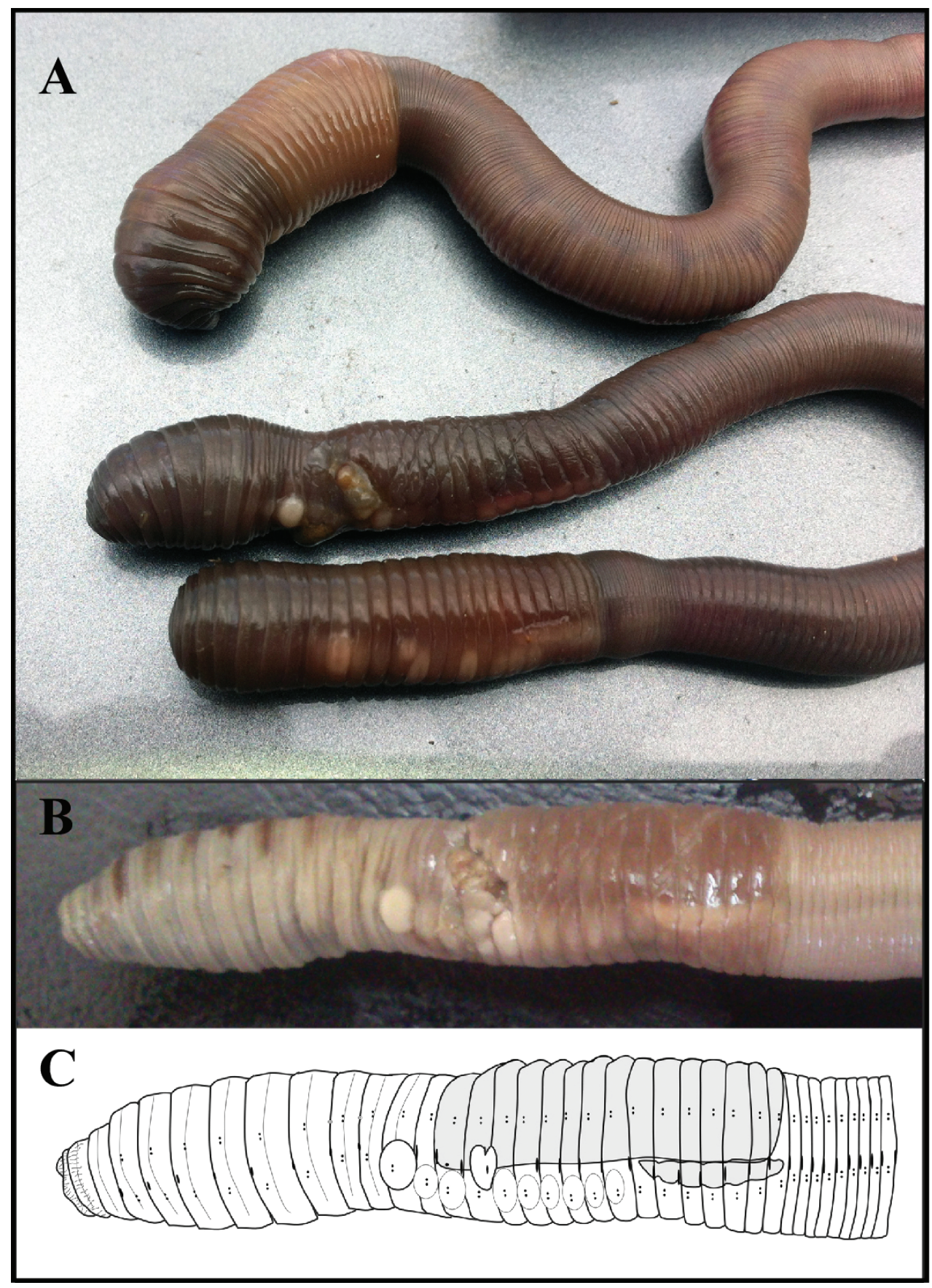

Figure 2. (A) Live specimens of $H$. joseantonioi sp.n. External morphology of a fixed specimen, shown in a picture $(\mathbf{B})$ and diagram $(\mathbf{C})$. 


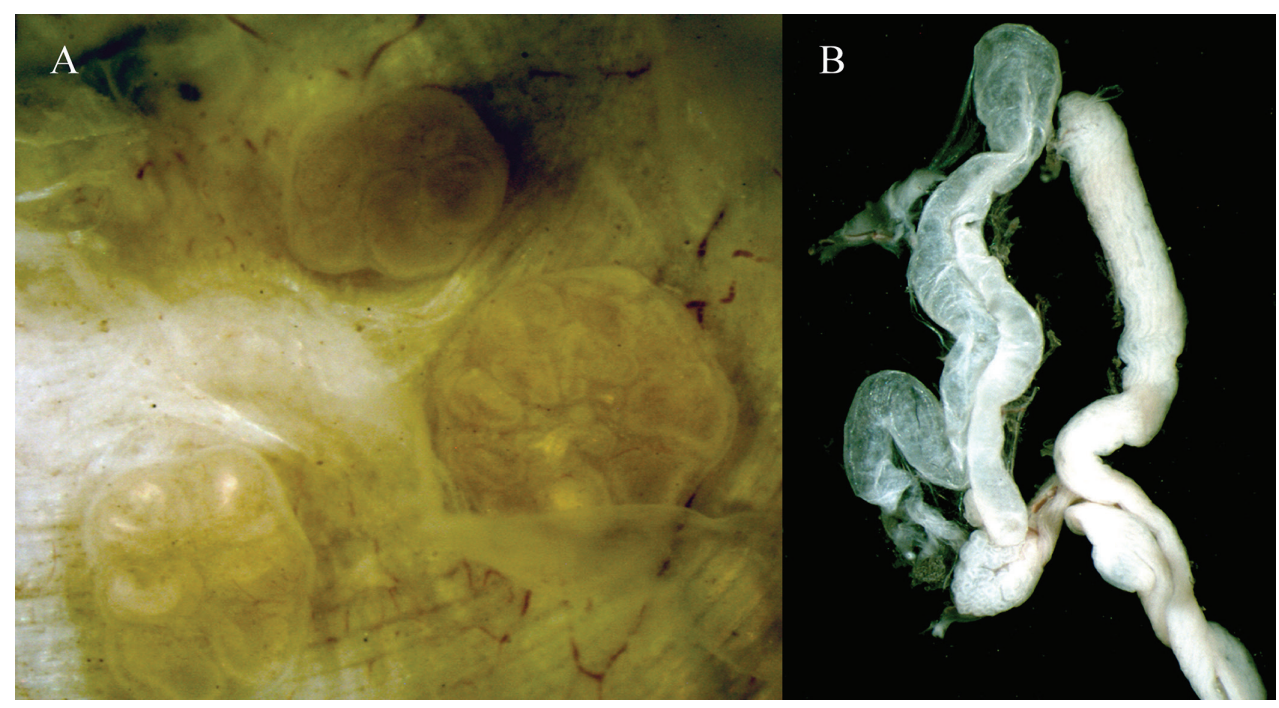

Figure 3. A) Spermathecae in segments 9 and 10. Note the double spermathecae in segment 10 of this specimen. B) Nephridial bladder of segment 7.

A posterior gizzard is not well differentiated. There is a slight dilatation of the oesophagus between 14 and 16, but it lacks the muscular wall and reinforcements of a true gizzard. First section of the intestine is not dilated.

Typhlosole begins around segments 20 and 21 with seven lamellae, which around segments $26-27$ increase to nine. From there they decrease gradually in number until segments $80-105$, where they fuse in a single lamella. The latter extends until segments 218-230, where the typhlosole ends.

Fraying testes and iridescent seminal funnels in 10 and 11 . Two pairs of voluminous, grainy seminal vesicles in 11 and 12. Ovaries and female funnels in 13, ovisacs in 14 .

Two pairs of spermathecae in intersegments $9 / 10$ and 10/11 (but apparently contained in segment 9 due to septum's backward displacement), the posterior pair bigger. They are sessile and disc-shaped, with multiple inner chambers which open to the exterior through a common pore, in the intersegments $9 / 10$ and 10/11. Some individuals show double spermathecae (each multicameral and with own pore), either in $9 / 10$ or 10/11 (Figure 3a).

Anterior nephridial bladders U-shaped with very close branches and no apparent cecum (Figure 3b). Bladders gradually flatten towards the end of the body, taking the usual elongated shape.

Distribution. Known only from its type locality.

Habitat. The specimens were collected at 10-20 cm deep in the soil in a cleared holm-oak wood, at the border between a dense forest of Quercus rotundifolia and a dryland farm. The soil had the following characteristics: $23.03 \%$ coarse sand, $8.06 \%$ fine sand, $5.33 \%$ coarse silt, $60.74 \%$ fine silt, and $2.84 \%$ clay, constituting a silty loam soil, carbon $(\mathrm{C}): 2.40 \%$, nitrogen $(\mathrm{N}): 0.24 \%, \mathrm{C} / \mathrm{N}: 10.18, \mathrm{pH}: 7.98$. Mean annual 


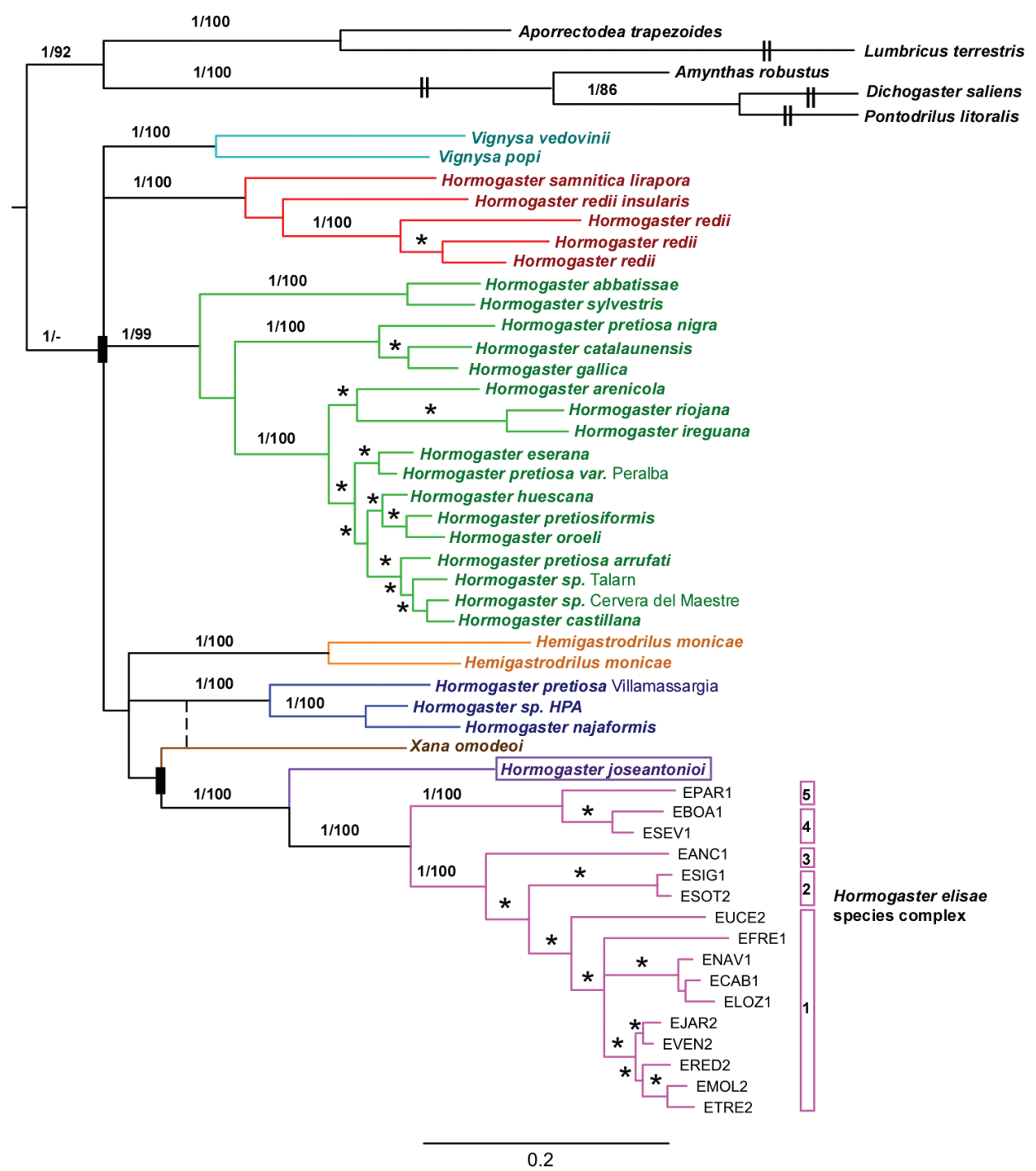

Figure 4. Bayesian inference of the phylogenetic tree on the concatenated sequence. Numbers above branches indicate posterior probability/bootstrap (of the Maximum Likelihood analysis) support values higher than 0.9/70 (shown as asterisks on terminal branches). Black rectangles show clades not recovered in both analyses (the alternative is shown with a dashed line). The cryptic species included in $H$. elisae are numbered from 1 to 5(following Novo et al. 2010).

temperature is $12.7^{\circ} \mathrm{C}$ and mean annual precipitation is $447.2 \mathrm{~mm}$, as indicated by the nearest weather station (in Herrera de Los Navarros, Zaragoza-23 km away http:// www.aragon.es/DepartamentosOrganismosPublicos/Organismos/InstitutoAragonesEstadistica/AreasTematicas/14_Medio_Ambiente_Y_Energia/ci.05_Clima_Datos_ climatologicos.detalleDepartamento?channelSelected=ea9fa856c66de310VgnVCM2 000002f551bacRCRD\#section 1). 
Etymology. The species is named after Jose Antonio Fernández Fernández, father of the first author Daniel Fernández Marchán and important contributor during the sampling campaign in which this species was discovered.

Molecular characters. Analyses were conducted on sequences from loci COI (10 individuals), 16S (2 individuals), 28S ( 2 individuals) and $\mathrm{H} 3$ (2 individuals) of the new species, combined with similar sequences from other hormogastrid species.

The resulting Bayesian inference of the phylogenetic tree is shown in Figure 4. Its topology was congruent with that of the Maximum Likelihood inferred tree, except for the different placement of $X$. omodeoi. $H$. joseantonioi sp.n. was recovered as a monophyletic clade, with the $H$. elisae species complex as a sister clade.

Uncorrected pairwise distances for the genes COI and 16S-tRNA for $H$. joseantonioi and the species within the same clade (with $H$. elisae divided into its five cryptic species) are shown in Table 2.

\section{Discussion}

Both morphological and molecular characters of $H$. joseantonioi sp.n. separate it clearly from all known hormogastrid species, the number of typhosole lamellae and the kind and location of the spermathecae being particularly distinctive. Those characters, while failing to resolve internal relationships within Hormogastridae, have been shown to be suitable for species diagnosis (Rota, 1993 on typhlosole importance; Novo et al. 2012 on spermathecae number to separate $H$. abbatissae from $H$. sylvestris).

The species $H$. riojana, while distantly related according to molecular phylogeny, shows many similarities in morphology to $H$. joseantonioi (Table 3 ). However, $H$. joseantonioi differ by its lower number of lamellae in its typhlosole and shorter tubercula pubertatis. Moreover it is longer and heavier. While the two species share a very similar position and shape of the spermathecae, some $H$. joseantonio $i$ individuals show an additional spermatheca in segment 10 (on the right or left side). These cases don't seem to be teratologic, as the supernumerary spermathecae have their own pore in the body surface and contain sperm, thus being fully functional.

Other hormogastrid species possess double or multiple spermathecae, but never of the multicameral, disc shaped kind.

The geographically closest species, $H$. castillana (from Puerto Querol, Castellón), is neither morphologically nor phylogenetically closely related (Table 3 ).

$H$. joseantonioi sp. n. appears nested on a weakly supported clade on the phylogenetic tree, consisting in Hemigastrodrilus monicae, Xana omodeoi, Hormogaster pretiosa from Villamassargia, Hormogaster najaformis (and HPA from Omodeo, see Novo et al. 2011) and Hormogaster elisae. Genetic distances were high in all cases (16.47-19.08\% for COI, $12.50-17.40 \%$ for $16 \mathrm{~S}$ ) according to the reference intervals given by Chang and James (2011). Aside from $H$. elisae, none of them showed significant morphological likeness to the new species, with the very different spermathecae configurations being noteworthy (Table 3). 


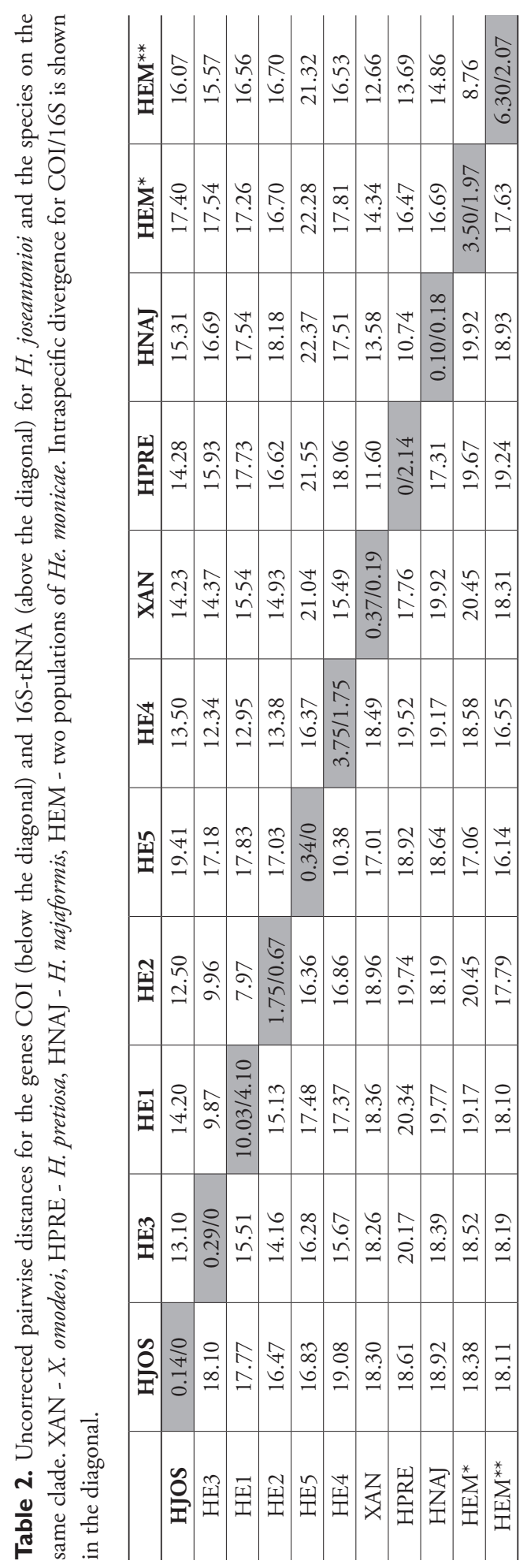


Table 3. Comparison of the morphological characters of $H$. joseantonioi sp. n. and some of the phylogenetically closest species (H. elisae, X. omodeoi and H. najaformis Qiu \& Bouché, 1998) plus the distantly related $H$. riojana and $H$. castillana Qiu \& Bouché, 1998. N. segments: number of segments. N. typhlosole lamellae: number of typhlosole lamellae. Body length, weight and number of segments refer to adult specimens.

\begin{tabular}{|c|c|c|c|c|c|c|}
\hline & H. joseantonioi & H. elisae & X. omodeoi & H. najaformis & H.riojana & H. castillana \\
\hline Colour & Brownish & Colourless & Colourless & Slightly greyish & Dark brownish & Brownish grey \\
\hline Clitellum & (13)14-28 & $\begin{array}{l}\text { (13)14(15)- } \\
26(27) 28\end{array}$ & $14-26$ & $13-31$ & $13,14,17-27,28$ & $1 / 14,15-29,1 / 230$ \\
\hline $\begin{array}{l}\text { Tubercula } \\
\text { pubertatis }\end{array}$ & $\begin{array}{c}1 / \mathrm{n} 22-27(1 / \mathrm{n} \\
28)\end{array}$ & $\begin{array}{l}22(23)- \\
25(26)\end{array}$ & $23-26$ & $20-26$ & (20)21-27 & $22-28$ \\
\hline Length $(\mathrm{mm})$ & $178-180$ & $92-200$ & $20-161$ & $188-230$ & 154 & $200-325$ \\
\hline N. segments & $305-369$ & $205-300$ & $190-230$ & $395-523$ & $243-278$ & $320-429$ \\
\hline Weight (g) & $7.05-11.57$ & $1.96-9.67$ & $0.59-4.23$ & $22.6-31.4$ & 6.57 & $12.85-29.38$ \\
\hline $\begin{array}{l}\text { Spermathecae } \\
\text { position (pores) } \\
\text { and appearance }\end{array}$ & $\begin{array}{c}9 \text { (see text) } \\
(9 / 10,10 / 11) \\
\text { Simple(double) } \\
\text { Multicameral, } \\
\text { disc shaped }\end{array}$ & $\begin{array}{c}9,10 \\
(9 / 10,10 / 11) \\
\text { Simple } \\
\text { Tubular }\end{array}$ & $\begin{array}{c}10,11 \\
(9 / 10,10 / 11) \\
\text { Simple Small, } \\
\text { globular }\end{array}$ & $\begin{array}{c}10,11 \\
(10 / 11,11 / 12) \\
\text { Multiple } \\
\text { Small, globular }\end{array}$ & $\begin{array}{c}9,10 \\
(9 / 10,10 / 11) \\
\text { Simple } \\
\text { Multicameral, } \\
\text { disc shaped }\end{array}$ & $\begin{array}{c}9,10(9 / 10,10 / 11) \\
\text { Simple Globular }\end{array}$ \\
\hline $\begin{array}{l}\text { N. typhlosole } \\
\text { lamellae }\end{array}$ & 9 & 5 & 12 & $15-17$ & 15 & $21-23$ \\
\hline $\begin{array}{l}\text { Thickened } \\
\text { septa }\end{array}$ & $\begin{array}{c}6 / 7,7 / 8,8 / 9 \\
(9 / 10)\end{array}$ & $\begin{array}{c}6 / 7,7 / 8,8 / 9 \\
(9 / 10)\end{array}$ & $\begin{array}{l}(6 / 7), 7 / 8,8 / 9, \\
9 / 10,(10 / 11)\end{array}$ & $\begin{array}{c}6 / 7,7 / 8,8 / 9 \\
(9 / 10)\end{array}$ & $\begin{array}{c}7 / 8,8 / 9,9 / 10, \\
(10 / 11)\end{array}$ & $\begin{array}{c}7 / 8,8 / 9,9 / 10, \\
(10 / 11)\end{array}$ \\
\hline
\end{tabular}

The H. elisae morphospecies was recovered as sister clade to H. joseantonioi sp. n. with high support. From a morphological point of view, most of their external characters overlap, except for a slightly longer clitellum and tubercula pubertatis, bigger average size and stronger pigmentation in $H$. joseantonioi sp. n. However, internal characters are very different and these species match neither in the number of lamellae in the typhlosole (five versus nine) nor in the structure of the spermathecae, which are tubular in $H$. elisae and disc-shaped and multicameral in $H$. joseantonioi. It's worth noting that $H$. elisae shares the backwardly displaced disposition of the $9 / 10$ septum.

Based on their phylogenetic and morphological relatedness, an origin of $H$. elisae from a common ancestor with $H$. joseantonioi sp. n. seems likely. This scenario is sensible from a biogeographical point of view, as the locality of the new species is intermediate between the ranges of $H$. elisae and the northeastern main hormogastrid range. A connection of emerged lands would have been possible from the Cretaceous-Tertiary boundary onwards (Andeweg 2002).

While $H$. joseantonioi status as a good species and its phylogenetic relationships seem quite clear, generic assignment is a more problematic matter. Novo et al. (2011) recovered the genus Hormogaster as paraphyletic in their molecular phylogeny, pointing out the need for a deep taxonomical revision of the family Hormogastridae, currently in preparation (author's work in progress).

Based on its distinctive morphology and geographic range, high genetic divergence and consistent recovery as a well-defined clade, Novo (2010) suggested the H. elisae 
species complex should be established as an independent genus. Due to the close phylogenetic position and morphological similarity of $H$. joseantonioi to this clade it could be argued they both should be included in the same genus.

At this stage it is more conservative to assign $H$. joseantonioi to the genus Hormogaster until the revision of the family is completed, which will allow to establish (if possible) a well-founded genera system on Hormogastridae. This work narrows the discontinuity between the North-Eastern and Central ranges of the Spanish hormogastrids. At the same time it highlights the importance of an intensive sampling of the area between Teruel and the center of the Iberian Peninsula (mainly zones of Soria and Guadalajara) to hopefully find new species along the hypothetical colonization route.

\section{Acknowledgements}

We are indebted to Jose Antonio Fernández Fernández for his help during the sampling campaign. Subject Editor Rob Blakemore and two anonymous reviewers helped to improve the manuscript. This research was funded by project CGL2010-16032 from the Spanish Government.

\section{References}

Akaike H (1973) information theory and an extension of the maximum likelihood principle. In: Petrov BN, Csaki F (Eds) Second lnternational Symposium on Information Theory. Budapest (Hungary). Akademiai Kiado, 267-281.

Andeweg B (2002) Cenozoic tectonic evolution of the Iberian Peninsula, causes and effects of changing stress fields. PhD Thesis, Vrije Universiteit Amsterdam, Amsterdam.

Álvarez J (1977) El género Hormogaster en España. Publicaciones del Centro Pirenaico de Biología Experimental 9: 27-35.

Blakemore RJ, Kupriyanova EK (2010) Unravelling some Kinki worms (Annelida:Oligochae ta:Megadrili:Moniligastridae) Part I. Opuscula Zoologica. 40: 3-18. http://opuscula.elte. hu/PDF/Tomus41_1/1_Op\%20-\%20Blakemore_Drawida.pdf

Blakemore RJ, Kupriyanova E, Grygier MJ (2010) Neotypification of Drawida hattamimizu Hatai, 1930 (Oligochaeta: Megadrili: Moniligastridae) and the first COI sequence from an earthworm type. ZooKeys 41: 1-29. doi: 10.3897/zookeys.41.374

Bouché MB (1972) Lombriciens de France, Écologie et Systématique. INRA, Paris, 671.

Briones MJI, Morán P, Posada D (2009) Are the sexual, somatic and genetic characters enough to solve nomenclatural problems in lumbricid taxonomy? Soil Biology \& Biochemistry 41, 2257-2271. doi: 10.1016/j.soilbio.2009.07.008

Chakrabarty P (2010) Genetypes: a concept to help integrate molecular phylogenetics and taxonomy. Zootaxa 2632: 67-68.

Chang CH, James S (2011) A critique of earthworms phylogenetics. Pedobiologia 54: S3-S9. doi: $10.1016 /$ j.pedobi.2011.07.015 
Chang CH, Lin S, Chen J (2008) Molecular systematics and phylogeography of the gigantic earthworms of the Metaphire formosae species group (Clitellata, Megascolecidae) Molecular Phylogenetics and Evolution 49: 958-968. doi: 10.1016/j.ympev.2008.08.025

Darriba D, Taboada GL, Doallo R, Posada D (2012) jModelTest 2: more models, new heuristics and parallel computing. Nature Methods 9(8): 772. doi: 10.1038/nmeth.2109

Dayrat B (2005) Towards integrative taxonomy. Biological Journal of the Linnean Society, 85(3): 407-415. doi: 10.1111/j.1095-8312.2005.00503.x

Díaz Cosín DJ, Briones MJI, Trigo D (1989) Descripción de una nueva especie de lombriz de tierra, Xana omodeoi (Hormogastridae, Oligochaeta) y sus implicaciones en la división de los Hormogastridae. Revue d'Écologie et Biologie du Sol 26: 225-231.

Excoffier L, Lischer HEL (2010) Arlequin suite ver 3.5: A new series of programs to perform population genetics analyses under Linux and Windows. Molecular Ecology Resources. 10: 564-567. doi: 10.1111/j.1755-0998.2010.02847.x

Fernández R, Almodóvar A, Novo M, Simancas B, Díaz Cosín DJ (2012) Adding complexity to the complex: New insights into the phylogeny, diversification and origin of parthenogenesis in the Aporrectodea caliginosa species complex (Oligochaeta, Lumbricidae). Molecular Phyogenetics and Evolution 64: 368-379. doiL 10.1016/j.ympev.2012.04.011

Fernández R, Kvist S, Lenihan J, Giribet G, Ziegler A (2014) Sine Systemate Chaos? A Versatile Tool for Earthworm Taxonomy: Non-Destructive Imaging of Freshly Fixed and Museum Specimens Using Micro-Computed Tomography. PLoS ONE 9(5): e96617. doi: 10.1371/ journal.pone.0096617

Heethoff M, Laumann M, Weigmann G, Raspotnig G (2011) Integrative taxonomy: Combining morphological, molecular and chemical data for species delineation in the parthenogenetic Trhypochthonius tectorum complex (Acari, Oribatida, Trhypochthoniidae). Frontiers in Zoology 8: 2. doi: 10.1186/1742-9994-8-2

Huson DH, Bryant D (2006) Application of Phylogenetic Networks in Evolutionary Studies, Molecular Biology and Evolution 23: 254-267. doi: 10.1093/molbev/msj030

Jamieson BG, Tillier S, Tillier A, Justine JL, Ling E, James S, McDonald K, Hugall AF (2002) Phylogeny of the Megascolecidae and Crassiclitellata (Annelida, Oligochaeta): combined versus partitioned analysis using nuclear (28S) and mitochondrial (12S, 16S) rDNA. Zoosystema-Paris-, 24(4): 707-734.

Katoh K, Standley DM (2013) MAFFT multiple sequence alignment software version 7: improvements in performance and usability. Molecular Biology and Evolution 30: 772-780. doi: $10.1093 / \mathrm{molbev} / \mathrm{mst} 010$

Michaelsen W (1900) Oligochaeta (Vol. 10). R. Friedländer und Sohn.

Novo M (2010) Algunos aspectos de la Biología Evolutiva de la Familia Hormogastridae Michaelsen, 1900: Filogenia, Filogeografía y Selección Sexual. Tesis de Doctorado, Universidad Complutense de Madrid, Madrid, España, 340 pp.

Novo M, Almodóvar A, Fernández R, Trigo D, Díaz Cosín DJ (2010) Cryptic speciation of hormogastrid earthworms revealed by mitochondrial and nuclear data. Molecular Phylogenetics and Evolution. 56: 507-512. doi: 10.1016/j.ympev.2010.04.010

Novo M, Almodóvar A, Fernández R, Giribet G, Díaz Cosín DJ (2011) Understanding the biogeography of a group of earthworms in the Mediterranean basin - The phylogenetic puzzle 
of Hormogastridae (Clitellata: Oligochaeta). Molecular Phylogenetics and Evolution. 61: 125-135. doi: 10.1016/j.ympev.2011.05.018

Novo M, Fernández R, Fernández Marchán D, Gutiérrez M, Díaz Cosín DJ (2012) Compilation of morphological and molecular data, a necessity for taxonomy: The case of Hormogaster abbatissae sp. n. (Annelida, Clitellata, Hormogastridae). ZooKeys 242: 1-16. doi: $10.3897 /$ zookeys.242.3996

Padial JM, De La Riba I (2010) A response to recent proposals for integrative taxonomy. Biological Journal of the Linnean Society 101: 747-756. doi: 10.1111/j.1095-8312.2010.01528.x

Pérez-Losada M, Ricoy M, Marshall JC, Dominguez J (2009) Phylogenetic assessment of the earthworm Aporrectodea caliginosa species complex (Oligochaeta: Lumbricidae) based on mitochondrial and nuclear DNA sequences. Molecular Phylogenetics and Evolution. 52: 293-302. doi: 10.1016/j.ympev.2009.04.003

Pérez-Losada M, Breinholt JW, Porto PG, Aira M, Dominguez J (2011) An earthworm riddle: systematics and phylogeography of the Spanish lumbricid Postandrilus. PLoS ONE 6: e28153. doi: 10.1371/journal.pone.0028153

Pop AA, Wink M, Pop VV (2003) Use of 18S, 16S rDNA and cytochrome c oxidase sequences in earthworm taxonomy (Oligochaeta, Lumbricidae). Pedobiologia 47: 428-433.

Pop AA, Cech G, Wink M, Csuzdi C, Pop VV (2007) Application of 16S, 18 S rDNA and COI sequences in the molecular systematics of the earthworm family Lumbricidae (Annelida, Oligochaeta). European Journal of Soil Biology 43: S43-S52. doi: 10.1016/j.ejsobi.2007.08.007

Qiu JP, Bouché MB (1998) Contribution to the taxonomy of Hormogastridae (Annelida: Oligochaeta) with description of new species from Spain. Documents Pedozoologiques et Integrologiques 4: 164-177.

Ronquist F, Huelsenbeck JP (2003) MRBAYES 3: Bayesian phylogenetic inference under mixed models. Bioinformatics 19: 1572-1574. doi: 10.1093/bioinformatics/btg180

Rota E (1993) Contribution to the taxonomy of the Hormogastridae (Annelida: Oligochaeta) with description of two new species from southern France. Journal of Natural History 28: 27-36. doi: 10.1080/00222939400770031

Sbordoni MC, De Matthaeis E, Alonzi A, Mattoccia M, Omodeo P, Rota E (1992) Speciation, genetic divergence and palaeogeography in the Hormogastridae. Soil Biology and Biochemistry 24(12): 1213-1221. doi: 10.1016/0038-0717(92)90096-G

Schlick-Steiner BC, Steiner FM, Seifert B, Stauffer C, Christian E, Crozier RH (2010) Integrative Taxonomy: A Multisource Approach to Exploring Biodiversity. Annual Review of Entomology 55: 421-38. doi: 10.1146/annurev-ento-112408-085432

Schwarz GE (1978) Estimating the dimension of a model. Annals of Statistics 6 (2): 461-464. doi: 10.1214/aos/1176344136

Stamatakis A (2006) RAxML-V1-HPC: maximum likelihood-based phylogenetic analyses with thousands of taxa and mixed models. Bioinformatics 22: 2688-2690. doi: 10.1093/ bioinformatics/btl446

Stephenson J (1930) The Oligochaeta. 978 pp.

Yeates DK, Seago A, Nelson L, Cameron SL, Joseph L, Trueman JWH (2011) Integrative taxonomy, or iterative taxonomy? Systematic Entomology 36: 209-217. 


\section{Appendix}

Supplementary material. GenBank accession numbers for all sequences used in the phylogenetic analysis, including outgroups. RF: sequences provided by Rosa Fernández.

\begin{tabular}{|c|c|c|c|c|}
\hline Species & COI & 16S-tRNAs & 28S-rRNA & H3 \\
\hline H. castillana QUE & HQ621989 & HQ621883 & HQ621960.1 & HQ622028 \\
\hline H. elisae 3 ANC & EF653870 & GQ409754.1 & GQ409657.1 & HQ622001 \\
\hline H. elisae $4 \mathrm{BOA}$ & GQ409661.1 & GQ409704.1 & GQ409656.1 & HQ622004 \\
\hline H. elisae $1 \mathrm{CAB}$ & GQ409689.1 & GQ409729.1 & GQ409653.1 & HQ622007 \\
\hline H. elisae 1 FRE & GQ409698.1 & GQ409723.1 & GQ409653.1 & HQ622009 \\
\hline H. elisae 1 JAR & GQ409665.1 & GQ409745.1 & GQ409653.1 & HQ622013 \\
\hline H. elisae $1 \mathrm{LOZ}$ & EF653888 & GQ409725.1 & GQ409653.1 & HQ622016 \\
\hline H. elisae $1 \mathrm{MOL}$ & EF653875 & GQ409732.1 & GQ409653.1 & HQ622019 \\
\hline H. elisae $1 \mathrm{NAV}$ & GQ409683.1 & GQ409730.1 & GQ409653.1 & HQ622021 \\
\hline H. elisae 5 PAR & EF653898 & GQ409709.1 & GQ409655.1 & HQ622024 \\
\hline H. elisae 1 RED & EF653881 & GQ409741.1 & GQ409653.1 & HQ622029 \\
\hline H. elisae 4 SEV & EF653905 & GQ409707.1 & GQ409656.1 & HQ622031 \\
\hline H. elisae 2 SIG & EF653893 & GQ409710.1 & GQ409654.1 & HQ622033 \\
\hline H. elisae 2 SOT & GQ409700.1 & GQ409716.1 & GQ409654.1 & HQ622034 \\
\hline H. elisae 1 TRE & GQ409678.1 & GQ409737.1 & GQ409653.1 & HQ622038 \\
\hline H. elisae 1 UCE & GQ409692.1 & GQ409720.1 & GQ409653.1 & HQ622039 \\
\hline H. elisae 1 VEN & GQ409671.1 & GQ409750.1 & GQ409653.1 & HQ622041 \\
\hline H. pretiosa arrufati & HQ621995 & HQ621889 & HQ621966.1 & HQ622040 \\
\hline H. pretiosa var. PRB & HQ621987 & HQ621881 & HQ621958.1 & HQ622026 \\
\hline H. pretiosa Villamassargia & HQ621998 & HQ621893 & HQ621969.1 & HQ622045 \\
\hline H. pretiosiformis oroeli & HQ621984 & HQ621877 & HQ621955.1 & HQ622022 \\
\hline H. redii redii & HQ621978 & HQ621871 & HQ621949.1 & HQ622012 \\
\hline H. redii redii & HQ621971 & HQ621863 & HQ621942.1 & HQ622000 \\
\hline H. redii redii & HQ621976 & HQ621869 & HQ621947.1 & HQ622010 \\
\hline H. redii insularis & HQ621996 & HQ621890 & HQ621967.1 & HQ622042 \\
\hline H. samnitica lirapora & HQ621993 & HQ621887 & HQ621964.1 & HQ622036 \\
\hline Hemigastrodrilus monicae & HQ621979 & HQ621872 & HQ621950.1 & HQ622014 \\
\hline Hemigastrodrilus monicae & HQ621982 & HQ621875 & HQ621953.1 & HQ622018 \\
\hline Hormogaster abbatissae & HQ621990 & HQ621884 & HQ621961.1 & HQ622030 \\
\hline Hormogaster arenicola & HQ621972 & HQ621865 & HQ621943.1 & HQ622003 \\
\hline Hormogaster catalaunensis & HQ621973 & HQ621866 & HQ621944.1 & HQ622005 \\
\hline Hormogaster eserana & HQ621977 & HQ621870 & HQ621948.1 & HQ622011 \\
\hline Hormogaster gallica & HQ621974 & HQ621867 & HQ621945.1 & HQ622006 \\
\hline Hormogaster huescana & HQ621980 & HQ621873 & HQ621951.1 & HQ622015 \\
\hline Hormogaster ireguana & HQ621994 & HQ621888 & HQ621965.1 & HQ622037 \\
\hline Hormogaster najaformis & HQ621985 & HQ621878 & HQ621956.1 & HQ622023 \\
\hline Hormogaster nigra & HQ621988 & HQ621882 & HQ621959.1 & HQ622027 \\
\hline Hormogaster pretiosiformis & HQ621983 & HQ621876 & HQ621954.1 & HQ622020 \\
\hline Hormogaster riojana & HQ621970 & HQ621862 & HQ621941.1 & HQ621999 \\
\hline Hormogaster sp. CER & HQ621975 & HQ621868 & HQ621946.1 & HQ622008 \\
\hline Hormogaster sp. HPA & - & HQ621892 & - & HQ622044 \\
\hline Hormogaster sp. TAL & HQ621992 & HQ621886 & HQ621963.1 & HQ622035 \\
\hline
\end{tabular}




\begin{tabular}{l|c|c|c|c}
\hline Species & COI & 16S-tRNAs & 28S-rRNA & H3 \\
\hline Hormogaster sylvestris & HQ621981 & HQ621874 & HQ621952.1 & HQ622017 \\
\hline Vignysa popi & HQ621991 & HQ621885 & HQ621962.1 & HQ622032 \\
\hline Vignysa vedovinii & HQ621986 & HQ621880 & HQ621957.1 & HQ622025 \\
\hline Xana omodeoi & HQ621997 & HQ621891 & HQ621968.1 & HQ622043 \\
\hline Amynthas robustus & EF077569.1 & EF490524.1 & EF490529.1 & - \\
\hline Dichogasters aliens & - & AF406573.1 & AY101560.1 & - \\
\hline Pontodrilus litoralis & - & AY340473.1 & - & - \\
\hline Lumbricus terrestris & HQ691222 & U24570 & HQ691218 & HQ691227 \\
\hline Aporrectodea trapezoides & RF & HQ621864 & RF & HQ622002 \\
\hline
\end{tabular}

